\title{
INTELIGÊNCIA POLICIAL: EFEITOS DAS DISTORÇÕES NO ENTENDIMENTO E NA APLICAÇÃO
}

Felipe SCARpelli de ANdrade

Departamento de Polícia Federal - Brasil

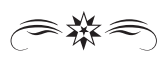

\begin{abstract}
RESUMO
O presente trabalho objetiva analisar o uso inadequado do termo "Inteligência" nas instituições públicas e privadas, sobretudo aquelas relacionadas à segurança pública, bem como demonstrar as consequências e desdobramentos que essa utilização indevida acarreta para a sociedade. Ao destacar o aspecto metodológico da atividade de inteligência e traçar aproximações e diferenças com a investigação e produção do conhecimento científico, procura-se desenvolver ideias que delimitam a atividade de inteligência em contraponto as demais atividades de assessoramento, fiscalização e a própria investigação. Nesse sentido, analisa-se, a partir de conceitos e legislação, a inviabilidade do uso de algumas técnicas de investigação, notadamente aquelas dependentes de autorização judicial, na atividade de Inteligência. Nesse sentido, expõe-se a necessidade dos organismos de inteligência de se apropriarem efetivamente de técnicas e processos de trabalho da Inteligência, concluindo ao identificar a oportunidade de aprendizado ao delimitarmos seu conceito para, então, evoluirmos sua teoria, com contribuição para a fundamentação e fortalecimento dos estudos sobre a atividade de Inteligência.
\end{abstract}

PALAVRAS-CHAVE: Segurança pública. Investigação. Inteligência. Metodologia da Produção do Conhecimento. Conceitos fundamentais.

\section{INTRODUÇÃO}

Este trabalho tem como objetivo discutir, através de análises, o uso do termo "Inteligência", que tem se tornado, cada vez mais, objeto de grande atenção por parte das instituições públicas e privadas. Ocorre que sua utilização desvirtuada acarreta uma série de consequências, pois tem se caracterizado pela falta de abordagem de questões fundamentais quanto a sua finalidade e conceitos basilares.

Nesse sentido, na medida em que se procura delimitar o conceito e a atividade de Inteligência, faz-se necessário compreender suas origens para então demonstrar sua natureza específica e seus principais aspectos. 
A partir do século XVI, com as relações diplomáticas surgindo na Europa, juntamente com as grandes navegaçóes e com o surgimento de novos métodos de obtenção e transmissão de informações, como a fotografia, código Morse, telégrafo, oficinas de impressão, comunicação criptográfica, além do grande fluxo de informações que transitavam, os organismos de inteligência, então incipientes, viram-se obrigados a se especializar e a trabalhar de forma mais racional e metódica.

Segundo Cepik (2003), estes métodos de obtenção de informações tornaram-se valiosos instrumentos para a expansão do conhecimento visando à proteção do Estado soberano frente às ameaças originárias do exterior, momento em que surgiu, conceitualmente, a Inteligência Estratégica, ou os serviços de inteligência, desenvolvidos para o exercício de funções coercitivas que diziam respeito a questões de guerra, diplomacia e ao policiamento e manutenção da ordem pública interna.

Entretanto, quando tratamos da metodologia da produção do conhecimento de Inteligência, foi somente a partir de meados da década de 40 que surgiram os primeiros conceitos, ou pelo menos as primeiras bases teóricas.

Importante destacar o momento singular da história da humanidade em que isso ocorreu. Foi exatamente no contexto da Segunda Guerra Mundial e da Guerra Fria que doutrinadores clássicos, como Sherman Kent, Washington Platt e Harry Hanson, estudaram e descreveram a necessidade de se produzir conhecimentos de Inteligência voltados, sobretudo, para apoiar as relações externas, na guerra e também na paz.

Neste ponto, destaca-se que a Inteligência como atividade especializada teve seu foco voltado para o Estado, constituindo-se num elemento importante para o Poder Nacional e criada para subsidiar gestores de alto escalão com conhecimentos ou informações estratégicas sobre o mundo exterior.

O primeiro estudioso que desenvolveu, descreveu e utilizou a metodologia para a produção do conhecimento foi Sherman Kent, pautado nos instrumentos das ciências sociais. Washington Platt veio em seguida, preocupando-se principalmente com as bases teóricas.

Não obstante o momento de instabilidade que o mundo enfrentava e, consequentemente a preocupação sobre informações de outros países, 
Platt (1974, p. 21) já considerava que os conhecimentos, produto da Inteligência, também eram úteis para os administradores de empresas. Vejamos:

A direção de empresas pode achar, também, interesse em algumas conquistas pioneiras dos artifices de Informações Estratégicas. Executivos de empresas e produtores de informaçóes enfrentam, todos, os problemas de estimar o que outros seres humanos podem fazer e farão. Necessitam tirar importantes conclusóes de dados insuficientes, em outras palavras, enfrentar o problema fundamental da produção de informaçôes. O empresário americano, que já demonstrou suma capacidade em aproveitar ideias de psicologia, engenharia, economia e outras disciplinas, quando serviam aos seus fins, encontrará aqui muitos problemas similares aos seus próprios, bem como novos métodos de solução.

Platt havia identificado à época, a importância da ferramenta de análise não apenas para os governos, mas para outros tipos de organizações, vislumbrando, assim, a possibilidade de atuação da atividade também no campo interno, inclusive voltada para empresários. Pensamento bem atual se considerarmos o ambiente caracterizado por uma disputa competitiva que essas organizações enfrentam hoje. Nesse sentido, o conceito de Inteligência pode e deve ser, também, aplicado a elas.

Entretanto, é notável que órgãos governamentais e privados têm se valido do nome Inteligência para executarem atividades que sempre fizeram e continuam fazendo, só que agora com o nome Inteligência, sem, contudo, utilizarem suas técnicas e metodologias. Como consequência exercem, sem dúvida alguma, atividade que não Inteligência.

É o caso de setores que lidam com fiscalização, resenhas, investigação social, coleta de informações, finanças, investigação, etc., os quais tendem a desvirtuar a atividade ou até mesmo ignorar a ciência da produção do conhecimento, esquecendo o principal objetivo da Inteligência - o assessoramento.

Não resta dúvida que a Inteligência é vista como área de interesse para qualquer organização no mundo dos negócios, assuntos públicos ou privados. Essa atividade é tida como elemento chave em um mundo contemporâneo onde as informações e a necessidade de processá-las aumentam em progressão geométrica, enquanto a capacidade de processamento não segue na mesma proporção. 
Não obstante, diversos setores do governo têm criado suas Inteligências com conceitos e definições próprias. A título de exemplo, podemos citar o caso brasileiro, onde as mesmas têm sido criadas sem o devido estudo, ou sem a preocupação com seus princípios básicos, como a Inteligência Prisional, Inteligência Criminal, Inteligência Policial, Inteligência ambiental, Inteligência cibernética, etc. Cada uma com seu próprio entendimento, com pouco ou sem qualquer embasamento teórico, contribuindo para a dificuldade de se compreender o que de fato é Inteligência.

Em se tratando dos setores governamentais é ainda mais notória a inclinação para se aplicar a (ilusão da) análise de Inteligência. De maneira geral, repartições públicas que lidam com atividades de processamento da informação, ou atividades fiscalizatórias os fazem sobre o falso manto da atividade de Inteligência. E este é apenas um pequeno problema se considerarmos, por exemplo, os órgãos responsáveis pela segurança pública.

Dentre as categorias em que se subdivide a atividade de inteligência, esta é ainda mais difícil de diferenciar, pois além de existirem diversos conceitos difusos definidos por legislação ou por especialistas, conforme veremos a seguir, não há consenso sobre este tema, tampouco sobre suas áreas de atuação, ou seu escopo.

Em meio a outras questões, isso ocorre porque entre a Inteligência e a investigação existem diversos pontos congruentes e por vezes indissociáveis, como, por exemplo, os dados e conhecimentos que subsidiarão ambas as atividades, mas há também importantes diferenças conceituais que devem ser compreendidas.

A seguir, a fim de demonstrar o que se propõe, serão demonstrados alguns conceitos que tratam de Inteligência Policial.

De acordo com o Manual de Inteligência Policial do Departamento de Polícia Federal - Volume I, inteligência policial é:

[...] a atividade de produção e proteção de conhecimentos, exercida por órgão policial, por meio do uso de metodologia própria e de técnicas acessórias, com a finalidade de apoiar o processo decisório deste órgão, quando atuando no nivel de assessoramento, ou ainda, de subsidiar a produção de provas penais, quando for necessário o emprego de suas técnicas e metodologias próprias, atuando, neste caso, no nivel operacional. (grifo nosso). 
A segunda parte desse conceito trata da Inteligência Policial como uma natureza diversa daquela em que a atividade de Inteligência foi concebida. $\mathrm{Na}$ verdade, quando tratamos da natureza executiva, no grifo acima exposto, estamos falando de investigação policial, ou investigação criminal, e não de Inteligência.

Reunir em um mesmo conceito a atividade de Inteligência e a investigação é um equívoco. Vejamos o entendimento da investigação criminal, na síntese de Denilson Feitoza Pacheco:

é um procedimento preliminar, de caráter administrativo e normalmente feito pela policia investigativa ('polícia judiciária'), por meio do qual se procura reunir um minimo de provas que permita ao acusador pedir o inicio do processo penal.

Esse conceito difere-se, pois, da atividade de Inteligência. Para a persecução penal, prova é tudo aquilo que podemos demonstrar por meios admitidos no direito, ao passo que para a Inteligência o que importa, nessa questão, são os fatos/premissas que basearam a convicção do analista, não havendo necessidade de se provar com base no Código processual penal brasileiro.

Já a Resolução no 1 , de 15 de julho de 2009, que regulamenta o Subsistema de Inteligência de Segurança Pública - SISP define que inteligência policial:

É o conjunto de ações que empregam técnicas especiais de investigação, visando a confirmar evidências, indicios e a obter conbecimentos sobre a atuação criminosa dissimulada e complexa, bem como a identificação de redes e organizações que atuem no crime, de forma a proporcionar um perfeito entendimento sobre a maneira de agir e operar, ramificaçôes, tendências e alcance de condutas criminosas.

Essa definição se mostra, de certo modo, não muito precisa, pois é possível inferir que trata também da investigação no momento em que se refere a "ações que empregam técnicas especiais de investigação, visando a confirmar evidências". A Inteligência deve ser tratada, primordialmente, como uma atividade de produção de conhecimentos, pelo que, apenas subsidiariamente, se valeria daquelas ações.

Não há dúvida que na medida em que se procura obter dados ou informações negadas, a Inteligência pode, de acordo com a metodologia da produção do conhecimento, utilizar operações de inteligência por meio de técnicas especiais de investigação. Mas é imprescindível que se 
observe o arcabouço jurídico, pois existem diversos limites legais para essas operações da atividade de Inteligência.

Nesse sentido, torna-se fundamental que se distinga corretamente a inteligência policial da investigação, para não haver futuros vícios na produção de provas ou na confecção de relatórios de inteligência. Vejamos o que nos traz Celso Ferro sobre a inteligência policial:

[...] a atividade que objetiva a obtenção, análise e produção de conhecimentos de interesse da segurança pública no território nacional, sobre fatos e situaçôes de imediata ou potencial influência da criminalidade, atuação de organizaçôes criminosas, controle de delitos sociais, assessorando as ações de policia judiciária e ostensiva por intermédio da análise, compartilhamento e difusão de informações.

Aqui temos um conceito interessante, pois não se perde a característica de assessoramento da atividade de Inteligência. Desse modo, a finalidade é consultiva na medida em que se procura produzir conhecimentos voltados para a segurança pública e que influenciem o processo decisório para a tomada de decisões no combate à criminalidade.

Portanto, a atividade de Inteligência é o processo científico especializado, levado a efeito através de metodologia própria da produção do conhecimento, com o objetivo de subsidiar, seja no nível tático, operacional ou em nível estratégico, decisões por parte de governantes, dirigentes de órgãos públicos ou privados. A contrainteligência, por sua vez, procura proteger esse conhecimento produzido.

Assim, este entendimento é amplo o bastante para ser aplicado a qualquer setor governamental ou privado e restritivo o suficiente para se preservar a natureza consultiva da atividade.

A recém-lançada (2013) Doutrina Nacional de Inteligência Penitenciária (DNIP) prevê, por exemplo, técnicas de disfarce, interceptação postal de correspondências, interceptação de sinais e dados, infiltração de agentes e desinformação.

Além de abordar questões relacionadas às técnicas especializadas de inteligência em detrimento de se ater à metodologia da produção do conhecimento, a nova DNIP deveria atentar para o fato de existir alguns impedimentos na legislação brasileira para a adoção de algumas dessas técnicas na atividade de Inteligência. 
O instituto da infiltração é um exemplo disso. Segundo ensinamentos de Rafael Pacheco (2007, p. 109), “o agente infiltrado é um funcionário da polícia que, falseando sua identidade, penetra no âmago da organização criminosa para obter informações e, dessa forma, desmantelá-la”. Nesse sentido, a infiltração de agentes policiais é ponderada como um artifício de meio de prova na investigação e não na Inteligência.

A infiltração é abordada em nosso ordenamento jurídico por meio da Lei $n^{\circ} 10.217 / 01$, que altera os artigos $1^{\circ}$ e $2^{\circ}$ da Lei no $9.034 / 95$ (Lei de Combate ao Crime Organizado). De acordo com a nova redação do art. $2^{\circ}$, inciso V, da Lei no 9.034/95, é permitida "em qualquer fase da persecução criminal a infiltração de agentes de polícia ou de inteligência, em tarefas de investigação, constituída pelos órgãos especializados pertinentes, mediante circunstanciada autorização judicial".

Embora o próprio texto legal faça menção ao agente de inteligência, é certo que não se pode requerer o instituto da infiltração ao judiciário com a finalidade de assessoramento, somente podendo fazê-lo na fase da persecução penal, para fins de produção de prova.

No esteio desse entendimento, é similar o caso da interceptação de sinais e dados. São dois os requisitos para tornar lícita a interceptação: ordem judicial e existência de investigação ou processo penal. Conforme se observa no artigo $5^{\circ}$, inciso XII da Constituição Federal:

Art. $5^{\circ}$ - Todos são iguais perante a lei, sem distinção de qualquer natureza, garantindo-se aos brasileiros e aos estrangeiros residentes no Pais a inviolabilidade do direito à vida, à liberdade, à igualdade, à segurança e à propriedade, nos termos seguintes:

(...)

XII - é inviolável o sigilo da correspondência e das comunicações telegráficas, de dados e das comunicações telefônicas, salvo, no último caso, por ordem judicial, nas hipóteses e na forma que a lei estabelecer para fins de investigação criminal ou instrução processual penal;

Conclui-se, assim, estar também afastada a possibilidade de interceptação para fins de assessoramento, pois é indispensável a prévia existência de investigação policial ou o processo penal, que só ocorre após o fato criminoso. 
Certamente, caso não houvesse restrição legal, as operações de inteligência que utilizam técnicas especializadas como a infiltração ou interceptação seriam importantes ferramentas para a Inteligência na elaboração de relatórios informacionais, pois se buscaria o aprendizado sobre a forma de agir de um grupo e a identificação das fontes de recursos utilizados pela organização criminosa. Contudo, em nosso ordenamento jurídico isso não é possível e, portanto, não seria adequado tratá-los em uma doutrina de Inteligência.

Outra questão no caso das interceptações e que deve ser levado a efeito é o uso dessas informações pela Inteligência. Os dados obtidos por interceptação, em princípio, não podem sequer ser utilizados em relatórios de Inteligência. A Lei no 9.296/96, em seu Art. $8^{\circ}$, define que deve ser preservado o sigilo das diligências:

A interceptação de comunicação telefônica, de qualquer natureza, ocorrerá em autos apartados, apensados aos autos do inquérito policial ou do processo criminal, preservando-se o sigilo das diligências, gravações e transcriçôes respectivas.

Portanto, o conhecimento obtido pela interceptação somente pode ser utilizado para atender a finalidade daquela autorização judiciária específica e durante a fase da investigação criminal ou na instrução processual penal.

Assim como no caso da infiltração, aqui também não há que se falar em interceptação com o objetivo de obter dados e informações para a Inteligência. $\mathrm{O}$ que vem ao encontro, mais uma vez, do entendimento de que técnicas especiais para obtenção do dado negado, notadamente aquelas que necessitam de autorização judicial, voltadas exclusivamente para a persecução penal, deveriam ser abordadas em um manual diferente, e não em Doutrina de Inteligência.

Essa tentativa de mesclar a atividade de Inteligência com a atividade investigativa policial é temerosa. O caráter duplo da atividade de inteligência policial, entendida como a atribuição de um órgão de inteligência policial, ao mesmo tempo em que produz conhecimentos para assessorar o processo decisório, atuar em investigações criminais, certamente implicarão em problemas tanto na área de Inteligência como na persecução penal.

É o caso da Operação Faktor, onde a Polícia Federal (PF) investigava Fernando Sarney, suspeito de fazer caixa dois na campanha de Roseana Sarney na disputa pelo governo do Maranhão no ano de 2006. Fernando Sar- 
ney foi indiciado por formação de quadrilha, gestão de instituição financeira irregular, lavagem de dinheiro e falsidade ideológica.

Em consequência dessa operação, a Polícia Federal gravou ligações que mostravam indícios de nepotismo praticados por Sarney, juntamente com Agaciel Maia.

Em 2011, o Superior Tribunal de Justiça anulou as provas que a PF havia encontrado por tê-las considerado ilegais. A investigação teve início com base em informações do relatório do Conselho de Controle de Atividades Financeiras (Coaf) que alertou a Polícia Federal e o Ministério Público sobre grandes saques em dinheiro vivo das contas de Fernando Sarney às vésperas do segundo turno da eleição de 2006.

Os ministros do STJ decidiram que dados obtidos pelo relatório do Coaf não eram suficientes para determinar quebra de sigilo. $\mathrm{O}$ entendimento invalidou as provas colhidas na operação, pois se concluiu que não houve indicação dos elementos mínimos que pudessem justificar a quebra de sigilo, sem que nenhuma outra investigação preliminar tivesse sido feita ou sem ter demonstrado a impossibilidade de fazê-la. Por isso, tratava-se de prova ilícita.

Esse é um exemplo cristalino onde se confunde a atividade de Inteligência com a investigação. $\mathrm{O}$ nome do relatório do Coaf é Relatório de Inteligência Financeira (RIF), e, por ser um relatório de inteligência, sua natureza é consultiva e não executiva.

Em outras palavras, a movimentação fora "atípica" e não podia ser considera "ilícita". Essa atipicidade, por si só, não poderia ser considerada como prova, mas poderia ensejar investigações outras que não medidas extremas como quebra do sigilo telefônico ou bancário. Nesse sentido, a quebra de sigilo baseada apenas em relatório do Coaf foi considerada inconstitucional.

Na medida em que o conceito da atividade de inteligência é um tema controverso, seu campo de atuação e, consequentemente, seu controle também não está esclarecido para diversos setores governamentais no País. E não exclusivamente entre os profissionais da área.

Relatórios de inteligência, justamente por serem destinados ao assessoramento do processo decisório e não ao processo penal, por sua característica de confecção, são invariavelmente de natureza sigilosa, regida pela Lei no ${ }^{\circ}$ 12.527/2011. 
O órgão de controle externo da atividade de Inteligência é denominado de Comissão Mista de Controle das Atividades de Inteligência (CCAI), composto por 06 (seis) integrantes, sendo 03 (três) deputados federais e 03 (três) senadores, além do Presidente da Comissão de Relações Exteriores e Defesa Nacional da Câmara dos Deputados e do Senado Federal.

Entretanto, o Ministério Público (MP) entende que cabe a ele o controle externo da atividade de Inteligência no âmbito policial. Essa questão motivou uma disputa entre a Procuradoria da República (PR-RJ) e a Superintendência Regional do Departamento de Polícia Federal do Rio (SR-DPF/RJ) no final do ano de 2010, no estado do Rio de Janeiro.

As duas instituições travaram na Justiça uma disputa em torno do acesso a todos os relatórios de inteligência produzidos pela unidade de inteligência policial federal local de 2008 a 2010, com base no Inquérito Civil Público no $137 / 2009^{1}$. O motivo era o não encaminhamento "ao MPF cópia dos relatórios de inteligência policial gerados no âmbito do SIP/CICOR, em total desobediência aos preceitos constitucionais e legais em vigor que tratam do exercício do controle externo da atividade policial.".

Eis, portanto, um cenário obscuro em relação à atividade de polícia judiciária e à atividade de Inteligência. Vejamos o que diz a legislação quanto ao controle externo de ambas as atividades.

No que tange ao controle externo da atividade investigativa, a Constituição da República Federativa do Brasil de 1988, em seu artigo 129, inciso VII, instituiu como função institucional do Ministério Público o controle externo da atividade policial, o qual seria regulado na forma da legislação complementar da União e dos Estados. Esse dispositivo enumera taxativamente as atribuições do Ministério Publico, e de acordo com seu inciso VII, o MP teria o dever/poder de realizar o controle externo no inquérito policial:

Art. 129. São funçôes institucionais do Ministério Público:

$$
\begin{aligned}
& I[\ldots] \\
& (\ldots)
\end{aligned}
$$

1 Inquérito Civil Público instaurado pelo Ministério Público Federal através dos Procuradores da República FÁBIO DE LUCCA SEGHESE e MARCELO DE FIGUEIREDO FREIRE, integrantes do Grupo de Controle Externo da Atividade Policial da Procuradoria da República no Estado do Rio de Janeiro, nos autos do procedimento administrativo $\mathrm{n}^{\circ}$ 1.30.011.004280/2009-58. 
VII - exercer o controle externo da atividade policial, na forma da lei complementar mencionada no artigo anterior; (grifo nosso).

Não há dúvida de que o controle externo exercido pelo Ministério Público é uma atividade de fiscalização, na prevenção, apuração e investigação dos fatos criminosos. Infere-se, pois, que o controle é relativo à investigação.

Portanto, como não se trata de questões afetas à atividade de persecução criminal, porque a atividade de Inteligência vai além das atividades de polícia judiciária, o controle não cabe ao MP.

No entanto, o Conselho Nacional do Ministério Público (CNMP) editou alteração da Resolução n 20 de 28 de maio de 2007, onde consta que cabe ao MP o controle externo de qualquer atividade policial, seja ela investigativa ou de Inteligência. Vejamos:

deve-se tornar claro que não há atividade policial que não se submeta ao controle externo, sob a nomenclatura de "Assuntos de Corregedoria", ou "Relatórios de Inteligência", ou quaisquer outras, que se criem com o objetivo de se furtar ao mandamento constitucional a ser desempenhado pelo Ministério Público.

Em contraponto ao entendimento do MP e considerando que os documentos de inteligência são confeccionados com a finalidade de assessoramento ao processo decisório e não ao processo penal, a realização do controle da atividade de inteligência é, de fato, feita de acordo com o art. $6^{\circ}$ da Lei n ${ }^{\circ} 9.883 / 99$ :

Art. $\sigma^{\circ} \mathrm{O}$ controle e fiscalização externos da atividade de inteligência serão exercidos pelo Poder Legislativo na forma a ser estabelecida em ato do Congresso Nacional. (grifo nosso)

$\$ 1^{\circ}$ Integrarão o órgão de controle externo da atividade de inteligência os lideres da maioria e da minoria na Câmara dos Deputados e no Senado Federal, assim como os Presidentes das Comissôes de Relações Exteriores e Defesa Nacional da Câmara dos Deputados e do Senado Federal.

$\mathfrak{S} 2^{\circ} \mathrm{O}$ ato a que se refere o caput deste artigo definirá o funcionamento do órgão de controle e a forma de desenvolvimento dos seus trabalhos com vistas ao controle e fiscalização dos atos decorrentes da execução da Política Nacional de Inteligência." (grifo nosso). 
Neste mesmo sentido cita-se o entendimento do Professor Joanisval Brito Gonçalves, consultor legislativo e da CCAI, "o controle realizado pela CCAI é funcional, ou seja, ela tem competência para fiscalizar todo o SISBIN. De fato, qualquer organização do Sistema que conduza atividade de inteligência está sujeita ao controle da CCAI.”2.

A Lei $n^{\circ} 9.883$ de 1999, instituiu o Sistema Brasileiro de Inteligência (SISBIN) e criou a Agência Brasileira de Inteligência (ABIN) com o objetivo de integrar as ações de planejamento e execução das atividades de Inteligência do país, com vistas a subsidiar o Presidente da República nos assuntos de interesse nacional.

Essa Lei determina, também, que todos os órgãos e entidades da Administração Pública Federal, com capacidade de produção de conhecimento de interesse das atividades de inteligência, deverão constituir o SISBIN, principalmente os responsáveis pela defesa externa, segurança interna e relações exteriores.

Portanto, sendo a PF um dos representantes do Ministério da Justiça no SISBIN, não cabe ao MP o controle de suas atividades de Inteligência, devendo fazê-lo o CCAI.

Equívocos relacionados a tais temas são comuns, tanto entre os integrantes do aparato de inteligência policial, quanto aos de outros setores governamentais, uma vez que há conceitos difusos da atividade de Inteligência. Ademais, a formação doutrinária no meio acadêmico-policial e nos bancos universitários não esclarece, satisfatoriamente, essa questão.

Essas situações corroboram a dificuldade com que os profissionais da área enfrentam, haja vista que a atividade de produção de conhecimentos, no sentido de apoiar as atividades de prevenção e repressão dos fenômenos criminais e para o assessoramento, não é tratada de maneira sistemática.

Isto não significa que não devam fazer Inteligência, pelo contrário, a utilização dessa atividade é fundamental em um cenário nacional e internacional complexo e instável. O aumento populacional, os avanços tecnológicos e as mudanças substanciais ocasionadas pelo processo de globalização, contribuíram e contribuem para o fortalecimento do crime organizado, crescimento do terrorismo, questôes ambientais, corrupção, entre outros.

2 Cf. entrevista de Joanisval Brito Gonçalves, realizada no Curso Superior de Inteligência Estratégica (CSIE), da Escola Superior de Guerra (ESG), em 03/06/2013. 
Mais uma vez, a questão é a falta de esclarecimento e o uso equivocado e continuado desses conceitos de Inteligência, que vão se cristalizando nas mentes das pessoas. Até mesmo os especialistas mais bem intencionados acabam aceitando-os como verdade.

O diagnóstico desse problema é a falta de investimentos do poder público em capacitação dos profissionais. Os "analistas de Inteligência" no Brasil, em sua grande maioria, não têm um arcabouço acadêmico e nem treinamento adequado nos seus campos específicos e, portanto, não há um emprego sistemático do conhecimento, onde os métodos são visíveis e verificáveis, permitindo aplicabilidade à metodologia própria.

Essa falta de estudos acadêmicos e múltiplos conceitos têm acarretado em uma série de operações policiais anuladas no âmbito do judiciário, órgãos governamentais se desentendendo e analistas de inteligência desenvolvendo trabalhos relacionados à persecução penal.

O processo de produção do conhecimento de Inteligência assemelha-se a um trabalho acadêmico, pois se procura construir um relatório baseado em premissas que o sustentem. Por conseguinte, esse processo está ligado diretamente à metodologia científica, uma vez que o analista procura imbuir-se de espírito cientifico aperfeiçoando-se nos métodos de investigação e aprimorando suas técnicas de trabalho através da busca da verdade.

Nessa esteira, a ciência como forma de produção do Conhecimento é especialmente interessante para o profissional de inteligência, já que busca identificar importantes atributos como o uso da hipótese, método objetivo, transparência, replicabilidade, revisão por pares, resultados provisórios e verificação das vulnerabilidades epistemológicas, trazendo maior confiabilidade ao produto final. Essa metodologia é traduzida pelo Ciclo da Produção do Conhecimento (CPC), com suas fases determinadas e delimitadas.

Certamente devemos levar em conta que o mundo hoje é diferente daquele vivido pelos autores clássicos da Inteligência tradicional, logo, é plausível dizer que a Inteligência também deve evoluir. A conexão entre ciência e prática, entre o mundo das teorias e o mundo da ação é fundamental.

Entretanto, existem conceitos basilares que são indissociáveis da atividade de Inteligência e que não devem ser modificados, haja vista os diversos 
problemas gerados pela falta de entendimento do tema. Desta forma, a seguir são apresentadas três importantes bases conceituais, que são abordadas tanto por autores clássicos como contemporâneos:

1) Foco na produção do conhecimento, através de metodologia própria.

2) Natureza consultiva, ou função de assessoria ao processo decisório.

3) Relação adequada entre o analista de Inteligência e o decisor, em função do risco de Inteligência politizada.

O uso de metodologia própria é significativamente importante, pois se a atividade de inteligência visa assessorar um gestor qualquer através da produção do conhecimento, faz-se necessário que se estabeleça meios para a consecução desse propósito. Esses meios baseiam a metodologia para a produção do conhecimento em inteligência.

Nesse sentido, Kent (1967, p. 55) afirma que é necessário método "peculiar ao trabalho de informações" referindo-se ao problema metodológico característico das pesquisas sociais. Por sua vez, Platt (1974, p. 131) deu bastante ênfase a esse processo, realçando o método cientifico aplicado à produção de informações, muito utilizado nas ciências e, em efeito na pesquisa para a produção de conhecimentos. Lowenthal e Shulsky convalidam as ideias de Kent e Platt quando identificam diversas bases teóricas para a confecção de relatórios de Inteligência.

Outro ponto importante para se entender Inteligência é a questão da natureza consultiva. Daqui pode-se extrair a finalidade da atividade. $\mathrm{O}$ que importa para a Inteligência é a construção do conhecimento no sentido de procurar maior aproximação com a verdade, lastreado em premissas que levem o analista à convicção quanto ao seu relatório, ou seja, decorre de trabalho intelectual obedecendo à metodologia da produção do conhecimento e que podem ser plenamente aproveitados para amparar decisões.

Difere-se, pois, daquela verdade judicial que significa somente o que é possível provar por meios admitidos no direito. Aqui, a norma constitucional produz relevantes reflexos na busca da verdade, já que estabelece parâmetros rígidos de licitude aos procedimentos investigatórios que visam desvendá-la. Lá, embora haja limites de atuação, o que importa é conhecer e não provar. 
Outro ponto crucial da atividade de Inteligência é a relação do analista produtor de um conhecimento com o seu tomador de decisão. Kent julgava que os produtores e utilizadores de informações devem estar suficientemente próximos das políticas para obter o máximo de orientação, mas não tão próximos a ponto de perderem sua objetividade e integridade de julgamento.

Lowenthal chama isso de "Inteligência Politizada" e faz alusão a essa relação com uma membrana semipermeável, onde os gestores têm liberdade para oferecerem avaliações que contrariam as análises de inteligência, mas os analistas não podem fazer recomendações sobre políticas com base na inteligência que produzem.

Nada mais sensato, uma vez que o papel do tomador de decisão é, obviamente, decidir. O analista, justamente por ser técnico e metodológico, não pode fazer o papel dos dois: analisar e decidir.

Ademais, quem produz um conhecimento sobre determinado tema tem aí sua delimitação. O gestor possui, em tese, conhecimentos outros que podem subsidiá-lo com informações de um cenário mais real, mais abrangente, podendo tomar a melhor decisão em um contexto mais amplo.

Estes são pontos chave da atividade, são concepções fundamentais para entender a Inteligência. Identificado esses pressupostos, não há necessidade de se criar ou procurar entender os inúmeros conceitos existentes, uns mais específicos, outros mais abrangentes, uns mais sucintos outros mais dilatados, tampouco existirá necessidade de buscar diferenciá-los das demais categorias em que se divide a atividade.

A falta de investimento em estudos e a propagação dos conhecimentos vêm causando a proliferação de falsos conceitos e usos inadequados de expressões, cuja explanação e discussão devem ser levadas aos centros acadêmicos.

O que se percebe, é que o significado de Inteligência está perdendo sua essência, seu núcleo. Existem definições que vão de encontro a sua natureza, a toda a evolução histórica que essa atividade sofreu pelo simples fato da vontade em se trocar a placa do setor de um determinado órgão pelo termo "Inteligência".

O desafio que se apresenta sobre a atividade de Inteligência não reside apenas na questão de procurar conceituá-la com precisão, mas de analisar 
a possibilidade do aprimoramento do emprego dos dados e informações obtidos, notadamente no âmbito da investigação, como suporte à produção do conhecimento, sobretudo em nível estratégico.

Dessa forma, a atividade poderia contribuir com mais eficiência ao assessoramento a gestores e autoridades governamentais, na formulação de políticas voltadas para as diferentes áreas que se opõem ao bom desenvolvimento do país.

A falta de uma cultura favorável à inteligência, associada ao desconhecimento da atividade e a sua visão distorcida, no âmbito da sociedade, dificulta e refletem no seu entendimento e na sua aplicação.

A Inteligência pode ser adaptada para muitos segmentos da sociedade, seja na área privada ou pública, mas é imperioso que entendamos seus alicerces, seus princípios, a fim de desenvolvermos de fato essa importante ferramenta de enfrentamento aos desafios contemporâneos que se apresentam. Do contrário, sem uma definição de Inteligência, sem uma clara ideia do que ela seja, se torna impossível desenvolver uma teoria que explique como ela trabalha.

Felipe Scarpelli de Andrade

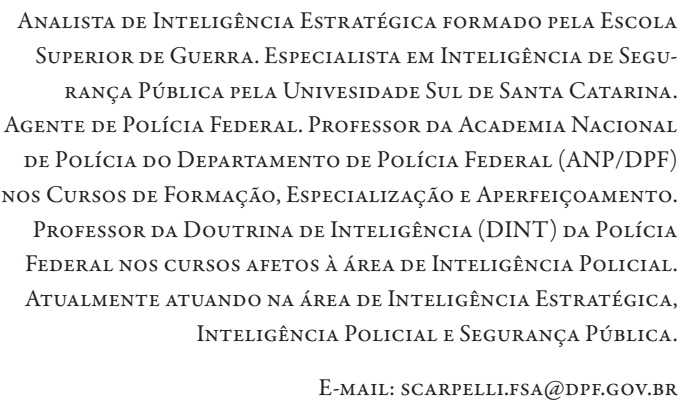

\section{ABSTRACT}

This essay aims to analyze the inappropriate use of the term "intelligence" in public and private institutions, as well as demonstrating the consequences and ramifications that this entails for misuse activity. By highlighting the methodological aspect of intelligence activity and trace similarities and differences with the investigation and production of scientific knowledge, we seek to develop ideas that limit intelligence activity in contrast to other advisory activities, supervision and own investigation. Accordingly, we analyze, from concepts and laws, the impossibility of the use of certain investigative techniques, especially those dependent on judicial authorization, to the Intelligence activity. In this sense, exposes the need of intelligence agencies effectively to appropriate 
techniques and work processes of intelligence, concluding by identifying the learning opportunity to circumscribe their concept to then evolve his theory, with contribution to the foundation and strengthening of the studies on the activity of intelligence.

KEYWORDS: Public safety. Research. Intelligence. Methodology of Knowledge Production. Fundamental concepts.

\section{REFERÊNCIAS}

\section{BRASIL. Constituição da República Federativa do Brasil de 1988.}

Presidência da República. Casa Civil. Brasília, 1988. Disponível em: < http://www.planalto.gov.br/ccivil_03/constituicao/Constituicao. htm>. Acesso em: 15 março 2013.

. Lei n⿳9 9.883, de 07 de dezembro de 1999. Presidência da República. Casa Civil. Disponível em: < http://www.planalto.gov. br/ccivil_03/Leis/L9883.htm>. Acesso em: 10 março 2013.

. Lei no 10.217, de 11 de abril de 2001. Presidência da República. Casa Civil. Disponível em: < http://www.planalto.gov.br/ccivil_03/ leis/leis_2001/110217.htm>. Acesso em: 20 março 2013.

. Lei no 9.034, de 03 de maio de 1995. Presidência da República. Casa Civil. Disponível em: < http://www.planalto.gov.br/ccivil_03/ leis/19034.htm>. Acesso em: 20 março 2013.

. Lei no 9.296, de 24 de julho de 1996. Presidência da República. Casa Civil. Disponível em: < http://www.planalto.gov.br/ccivil_03/ leis/19296.htm>. Acesso em: 10 março 2013.

. Lei no 12.527, de 18 de novembro de 2011. Presidência da República. Casa Civil. Disponível em: < http://www.planalto.gov. br/ccivil_03/_ato2011-2014/2011/lei/l12527.htm>. Acesso em: 01 março 2013.

CEPIK, Marco A. C. Espionagem e Democracia. Rio de Janeiro: FGV, 2003.

COMISSÃO NACIONAL DO MINISTÉRIO PÚBLICO. Comissão de Aperfeiçoamento da Atuação do Ministério Público no Sistema Carcerário e no Controle Externo da Atividade Policial. Disponível em: <http://www.cnmp.gov.br/portal/images/stories/ Noticias/2013/Arquivos/alteracao_resolucao_20.pdf>, acesso em 30 de abril de 2013. 
FEITOZA, Denilson. Direito Processual Penal: teoria, crítica e práxis.

5. ed. rev., ampl., e atual. Niterói: Impetus, $2008^{a}$.

FERRO JÚNIOR, Celso Moreira. A Inteligência e a Gestão da Informação Policial. Editora Fortium. Brasília/DF: 2008.

JUSBRASIL. Inteiro teor do Habeas Corpus No 191.378 - DF

(2010/0216887-1). Disponível em: <http://www.jusbrasil.com. br/jurisprudencia/21026335/habeas-corpus-hc-191378-df-20100216887-1-stj/inteiro-teor>, acesso em 30 de abril de 2013

KENT, Sherman. Strategic Intelligence for American World Policy.

Princeton: Pricenton University Press, 1949.

LOWENTHAL, Mark M. Intelligence: from secrets to policy. Washington, DC: CQ Press, 2003.

PACHECO, Rafael. Crime Organizado: Medidas de Controle e Infiltração Policial. Curitiba: Juruá, 2007

SENASP. Resolução No 1, DE 15 DE JULHO DE 2009. Disponível em: <http://cgi.infoseg.gov.br/sisp/sisp_resolucao_01JUL2009.pdf>, acesso em 20 de março de 2013.

SHULSKY, Abraham N. Silent warfare: understanding the world of Intelligence.Washington, DC: Brassey's INC, 2002.

SILVA, Wellington Clay Porcino. O conceito de atividade de inteligência policial. Jus Navigandi, Teresina, ano 17, n. 3444, 5 dez. 2012 . Disponível em: <http://jus.com.br/revista/texto/23165>. Acesso em: 3 maio 2013.

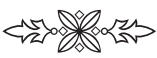

